\title{
Noções conceituais da sexualidade humana num recorte foucaultiano
}

\author{
Renan Custódio do Nascimento ${ }^{I}$
}

\begin{abstract}
RESUMO - Este artigo apresenta discussão acerca da sexualidade humana, em perspectiva histórico-cultural, com base na obra de Michel Foucault, História da sexualidade, que evidencia a importância e o papel da linguagem na formação de dispositivos, sobrepondo-se à visão biológica da sexualidade.
\end{abstract}

Palavras-chave: sexualidade, poder, saber, dispositivos, linguagem.

\section{Purpose conceptual of human sexuality in the Foucault's work}

\begin{abstract}
This paper presents a discussion about human sexuality, in an historic culture perspective, from Michel Foucault's work - Sexuality History, evidencing in a biological point of view the sexuality, the importance and role of the language in the formation of mechanisms.
\end{abstract}

Key words: sexuality, power, knows, mechanisms, language.

A escolha de Michel Foucault em sua trilogia sobre a sexualidade decorre da proposição de entendê-la com base no recorte lingüístico, derivado dos processos histórico-culturais, em contrapartida à predominância do paradigma biológico. Com efeito, a proposição "foucaultiana", no mínimo, preserva uma noção de sexual, destituindo os "donos do saber sexo", como a igreja, a ciência, a economia, ou quaisquer outros interesses que circunscrevam os limites do sexo. Nesse sentido, a obra de Foucault lança luz à concepção do sexual, sem impor-lhe determinismos.

Sua arqueologia dos saberes e sua genealogia dos poderes da sociedade contemporânea não visam à crônica dos comportamentos sexuais por meio das épocas e civilizações, em recorte horizontal dos acontecimentos. Ao contrário, sua obra visa à produção da verdade, juntamente com a vontade de saber, em que o poder sobre o sexo se enredou e produziu-se; mais ainda, investiga a maneira pela qual a verdade é produzida e difundida e seu poder de penetração nos vários

${ }^{1}$ Psicólogo clínico, mestre em Psicologia pela Universidade Católica de Brasília, especialista em Psicologia Hospitalar, em Psicossomática e em Educação sexual, é professor de Psicofisiologia no UniCEUB.

Universitas Ciências da Saúde - vol.03 n.01 - pp. 65-72 
segmentos da sociedade. Assim, em "História da sexualidade", Foucault busca investigar a maneira pela qual se formou o saber sobre o sexo, multiplicaram-se os discursos que o tornaram como objeto, e as razões pelas quais se atribuiu a significativa valoração à verdade que tais discursos pensavam produzir.

Em "A vontade de saber", Foucault vale-se de importante conceito, que é a constituição de dispositivo apresentado na "Microfísica do poder"(Foucault, 1979), retratado como o dispositivo da sexualidade. Essa noção constitui conjunto heterogêneo de discursos, leis, enunciados, organizações arquitetônicas, ditos e não ditos, constituindo uma rede pela qual se estabelecem relações entre esses elementos. São estratégias de relações de força, sustentando tipos de saber e sendo por elas sustentado. Para ele, o dispositivo está inscrito num jogo de poder, sempre, no entanto, ligado a configurações de saber que dele nascem, mas que o condicionam igualmente.

Com efeito, por meio desse dispositivo, é possível compreender como o silêncio (o não dito) produziu vestígios subjacentes às práticas sociais, construindo conceitos, idéias, normas que passaram a determinar o certo e o errado. Esse silêncio não é, necessariamente, o que esses discursos não dizem, mas é o conjunto de estratagemas utilizados para a produção dos discursos. Na perspectiva de Foucault, pode-se considerar que o modo como a sociedade lida com o poder e o saber realiza-se por meio da montagem de dispositivos discursivos. Isto é, para conhecer uma sociedade, sua organização, ou uma época, é necessário descobrir o que ela diz, como diz, porque o diz, para que o diz, a quem diz, como foi possível esse dizer, de onde o disseram, que práticas o suscitaram e foram suscitadas por esse dizer.

Foucault afirma que, desde a época clássica até o início do século XVII, vigorava razoável franqueza das práticas sexuais e que, para a mentalidade arcaica, o sexo fazia-se presente no campo do sagrado e não do profano. Essas práticas sexuais eram despojadas de disfarce e segredo. Contudo, as transformações estruturais do século XII, sobretudo de caráter religioso, influenciaram a postura que se tornou cada vez mais pessoal e menos comunal, mais interna que explícita, ou seja, mais privada que pública.

A respeito da repressão sexual estabelecida na Era Vitoriana, no século XIX, Foucault propõe pensá-la por meio das suas práticas, das idéias difundidas em sua decorrência, das instituições que regulamentam essas práticas, juntamente com todo o conjunto explícito de interdições e censuras. Para o autor, a ilusão não reside apenas na interdição sexual da época mas também em fazer dessa ilusão o elemento fundamental e constituinte de acordo com o qual se poderia escrever

${ }^{1}$ História da sexualidade: a vontade de saber (Foucault, 2001) 


\section{Sexualidade humana num recorte foucaultiano}

a história do que foi dito do sexo a partir da Idade Moderna. Nesse sentido, Foucault parece não dar tanta ênfase à repressão do sexual em si, mas, sim, à incitação permanente a que se fale do sexual, seja por meio do dito, do como é dito, bem como do não dito.

Para tanto, a idéia de repressão baseia-se no princípio do poder, não no sentido do poder que limita, confina, reprime, constrange, mas como princípio de interdição e incitação ${ }^{2}$. Assim, não se caracteriza inteiramente o poder quando se busca explicá-lo por sua função repressiva e, sim, pelo gerir a vida dos homens, controlando-a em suas diretrizes e ações. Pode-se conceber que a repressão está imbricada nos processos de interdição de tal forma que tanto o poder, o saber e a sexualidade são perpassados e ligados pelos processos da repressão. É, portanto, nesse contexto que se encontra o dispositivo da sexualidade a serviço das estratégias de poder e do saber, apresentando a produção da sexualidade como um saber que diz o verdadeiro e o falso acerca do sexo.

Por volta do século XVIII, instala-se a tal incitação política, técnica, econômica a falar do sexo, o discurso sexual, por meio de especificações das pesquisas quantitativas ou casuais. É dessa maneira que o sexo passou a ser regulado pela medicina, pedagogia, psiquiatria e justiça penal, despertando seu interesse, tornando-se caso de polícia no sentido de majoração ordenada das forças coletivas e individuais. Nesse período, há o surgimento das técnicas de poder que regulamentam a população como problema econômico e político na relação entre população, riqueza, mão de obra, força de trabalho, etc. O dispositivo do sexo torna-se o centro das questões políticas e econômicas sobre controle da natalidade, faixa etária ideal para o acasalamento e casamento, celibato, etc.

Para Foucault, o sexo fica subordinado a essas "instituições", as quais, com o intuito de organizar e apropriar-se de seus saberes, obrigam-no à existência discursiva doutrinária. Isto é, o sexo fica "coisificado" numa ordem discursiva, sujeita a dispositivos e sendo o próprio dispositivo em face do seu significante. A instituição pedagógica, por exemplo, encarregou-se das crianças, codificou conteúdos e qualificou os locutores para a educação sexual, no entanto produziu a formal "deseducação sexual".

Já a medicina, incumbiu-se das mulheres - com sua histerização - e dos demais "doentes dos nervos". À psiquiatria coube a busca das doenças mentais, da relação delas com a prática do onanismo, os exageros sexuais, as fraudes contra a procriação e a "psiquiatrização" das perversões. Mobilizou-se numa nosografia sexual, explorando a patologia daquilo que nem se conhecia o seu "normal". O

\footnotetext{
2"Não existe algo unitário global chamado poder, mas unicamente formas díspares, heterogêneas, em constante transformação. Opoder nãoé um objeto natural, uma coisa; é uma prática social, e como tal, constituída historicamente"(Foucault, 1990-Microfisica do poder).
} 
sexo, em sua noção biológica, restringe-se à esfera do instinto e da função fisiológica, portanto está submetido a desvios e disfunções. Esta ainda é forte herança às modernas e ingênuas terapias sexuais. Finalmente, a justiça penal ocupouse dos controles que filtram a sexualidade dos casais, dos filhos e dos pais, irradiando discursos preocupados em proteger a população de perigo incessante e ameaçador o qual pode corromper tradições e perverter pessoas de boa fé.

Com efeito, para Foucault, esses dispositivos de interdição foram constituindo, do ponto de vista histórico, dois grandes procedimentos produtores da verdade do sexo: o primeiro, pela discursividade científica; o segundo, pelo procedimento da confissão. Ou seja, o sexo estaria preso aos invólucros das instituições médicas e pedagógicas ou nos confissionários das igrejas, pois é a confissão que liga a verdade ao sexo pela expressão obrigatória e exaustiva de um segredo individual.

Tal perspectiva desenrolou-se na relação com o trinômio poder - saber prazer, pois a confissão é um ritual discursivo no qual o sujeito que fala coincide com o sujeito do enunciado. Ritualizou-se em processo econômico, na relação de poder, pois não se confessa sem a presença de instância de autoridade detentora da condenação e/ou da absolvição. Assim, os integrantes dessa relação constituíam partes do real ou imaginário de um jogo de sistema de forças - o trinômio determinante na construção da interdição sexual.

Com base nesse pressuposto, o sexo, como matéria privilegiada da confissão, evidencia um paralelismo entre os rituais de confissão com os esquemas da regulamentação científica por meio da codificação clínica entre o fazer falar e o confessar, tudo reinscrito no campo das "observações científicas". Nesse sentido, a psicologia insere-se como um dos efeitos do dispositivo da sexualidade.

É curioso que a psicanálise tenha libertado a sexualidade da ocultação desde o período clássico, com os "Três ensaios sobre a teoria da sexualidade" e com o "pequeno Hanz", contudo, segundo Foucault, a psicanálise também assimila o rito da confissão, definindo a sexualidade como "natureza", demandando, portanto, necessidade de análise para recuperação dos traumas sexuais. Portanto, refuta-se a tese de que a psicanálise teria realmente libertado a sexualidade da repressão, característica da Era Vitoriana, e evidencia como a modernidade, por meio da oficialização da ciência sexual, incluindo a psicanálise, regulamentou e geriu o trinômio poder - saber - prazer.

É importante considerar que a psicanálise é a área do conhecimento que permitiu tratar da sexualidade humana de forma mais isenta dos vieses que sempre a envolveram; pode considerar-se o sexo antes e depois de Freud. O discurso sobre o sexo ocultou continuamente o que dele se falava; havia todas as precauções e análises meticulosas como procedimento destinado a esquivar a verdade insuportável e excessivamente perigosa sobre o sexo. No entanto, a partir dos 


\section{Sexualidade humana num recorte foucaultiano}

"Três ensaios sobre a teoria da sexualidade", há apresentação da noção da sexualidade infantil, o que é por demais avançado para a época, o conceito de pulsão e as primeiras tentativas de classificação nosográfica que contemplasse as diferenças entre a neurose e a perversão. O estudo da histeria abria inserção do sexual, trazendo à tona o proibido, pois, mesmo a psicanálise, que lançou luz à questão da sexualidade, esteve a serviço de uma "ciência sexual".

Entretanto, o ato da fala no divã diferencia-se em muito da confissão, pois, na cena analítica, o sujeito do enunciado é o mesmo que fala, inserindo-se no conjunto de representações interditórias das quais ele mesmo se condena, julga, absolve e repudia durante sua re-significação. Já no confessionário, o pecador submete-se à ordem da confissão ao outro, a uma autoridade que o julga, condenando-o ou absolvendo-o.

Considerando as antigas interdições, o século XIX recebe herança problemática, pois continuam valendo as velhas alianças interditórias e veladas. Essa época foi marcada pela condenação ao adultério, pela perseguição aos hábitos solitários, pelo ataque à sexualidade infantil e pela mobilização dos pedagogos e médicos para erradicar o onanismo. Assim, o sexo garante seu status no segredo, no escondido, sob os dispositivos da vigilância permeados pelo medo e pela culpa. A família dessa época é monogâmica, conjugal e heterossexual. O seu prolongamento é representado pelas instituições escolares e psiquiátricas, manejando o jogo de poderes e prazeres. Incluídas nesse contexto as preocupações com as degenerescências de raças, a ciência sexual constituiu, no século XIX, uma das disciplinas cruciais para os dispositivos do "biopoder e da bio-história"3. Com efeito, os discursos sexológicos participam da estratégia geral de sexualidade controlada, servindo aos movimentos de racismo e eugenia oriundos da modernidade.

Com o aval do saber "científico da sexologia", surge nova hierarquia pautada na natureza biológica por meio de suas diferenças. Dessa forma, a ciência do sexual inscreveu-se em processo político que considera a qualidade de sua população como riqueza nacional e potencialidade das reservas naturais. Assim, segundo Foucault, em nome da urgência biológica e histórica, justificam-se o racismo e a eugenia baseados em "verdades". É dessa maneira que os séculos XIX e XX garantem o inumerável lucro econômico por meio da pedagogia sexual, da medicina, da prostituição, da pornografia que se vinculam, na mesma configuração, à concentração analítica do prazer e do poder que o controla.

\footnotetext{
${ }^{3}$ Biopodere bio-história referem-se a conceitos apresentados por Joel Birman, em que a tecnologia biológica serve como diretriz a parâmetros políticos, econômicos e sociais; são dispositivos meticulosamente produzidos no campo de um projeto político resultante das estratégias da modernidade (Birman, 2000).
} 
Um exemplo típico desse poder da ciência sexual pode ser observado nas exposições de Charcot na Salpêtriére, frente às observações dos exames públicos, dos interrogatórios, das manipulações que incitavam o saber, baseado na descrição nosográfica, pela exposição da paciente à autoridade, em face de sua histerização. Anos mais tarde, o laboratório sexual de Masters e Johnson, nas décadas de sessenta e setenta, com observações eletrofisiológicas da resposta sexual durante o acasalamento, evidenciou o corpo como se determinasse o sexo: os limites do corpo estabeleceriam o tamanho e a expressão do sexo. Na contracultura disso, o sexo torna-se o resultado da historicidade, em que o corpo recebe a memória de significantes e significados, passando a ser investido de representações. Nesse sentido, o corpo subsume-se ao imaginário coletivo juntamente com todas as representações do real e do imaginário ${ }^{4}$.

A história da sexualidade baseada nos mecanismos da repressão decorre do nascimento das proibições, concomitantemente com a valorização exclusivista da sexualidade adulta e matrimonial como imperativos de decência e normalidade, advindas do século XVII, em que há a esquiva do corpo e os pudores imperativos na linguagem. Assim, segundo Foucault, surge a "tecnologia da carne", que se relaciona com as grandes proibições, de uma teologia moral, que, controlada pela pastoral cristã na Idade Média, centralizava o tema da carne como prática de confissão. Era perpassada pelo dispositivo da aliança, caracterizada por sistema de matrimônios, desenvolvimento de parentescos, títulos, nomes e bens. Este dispositivo estrutura-se em torno de sistemas de regras, vinculados ao direito com o objetivo de produzir a trama das relações e manter a lei que as rege.

Essa tecnologia estava a serviço dos métodos católicos e protestantes, no exame de consciência - procedimentos de análise e de colocação em discurso da "concupiscência". As técnicas foram herdadas do século XVI até serem cristalizadas nos dois séculos posteriores. Na tentativa de reformular o modelo de repressão sexual existente, surge, nos séculos XIX e XX, a "tecnologia do corpo ou do sexo". Ela é marcada pela incitação a falar do sexo, entretanto gira em torno das instituições médicas, da noção biológica de normalidade sexual; o problema da vida e da doença substitui a questão da morte e do castigo eterno dos séculos anteriores. A ciência do sexual transferiu a tecnologia da carne para a tecnologia do organismo.

A mudança para a tecnologia do sexo, por meio do organismo que pode ser examinado, investigado, dissecado, possibilitou a separação entre a medicina geral e a sexual. A mudança possibilita compreender o instinto sexual, as anomalias constitutivas, os desvios adquiridos, etc. Assim, as relações sexuais, as doenças venéreas, as perversões, o controle de natalidade passam a ser regidos por

${ }^{4}$ Apostila do curso de Formação em Psicossomática. Nascimento, 2004. 
responsabilidade biológica. Essa tecnologia ordena-se por meio da pedagogia, codificando a sexualidade infantil em conteúdos próprios e impróprios, qualificando os locutores e, finalmente, a medicina com o domínio sobre as doenças dos nervos e a fisiologia sexual das mulheres. Essas instituições inventaram a eugenia e a medicina das perversões.

No dispositivo da tecnologia do sexo, o corpo (organismo) é tomado como objeto de saber e elemento nas relações de poder. Esse dispositivo desenvolveuse por meio de quatro estratégias específicas, segundo Foucault: a sexualização das crianças, a histerização da mulher, a especificação dos perversos e a regulação das populações. Como conseqüência, a proposta da "educação sexual" parte do princípio de que há a falta de educação. Ora, não é a educação o processo de formatação de significantes e significados? Assim, qualquer proposta de educação sexual é paradoxalmente falaciosa. Outra grande dúvida que se interpõe é quem seriam os locutores qualificados para essa hipotética educação. Os celibatários? Os que tratam as doenças? Os pedagogos sexuais?

O referencial adotado no século XX para a formação sexual ainda parte da "biologização" sexual (resquícios da tecnologia do corpo), ou seja, aquele que deteria a compreensão da biologia sexual deteria o saber sexual; assim, estaria credenciado pelo "Estado" a falar, tocar, argüir; o saber imputado ao médico estende-se ao ginecologista, ao psiquiatra, ao psicólogo e, finalmente, ao pedagogo. É importante lembrar que esta pretensa educação sexual ainda serviria como dispositivo de controle contra as perversões, os exageros, os desvios e as doenças. Isto é, a oficialização dessa educação ocorre pela evidenciação de tudo o que é ruim e evitado; ensina-se o que não se pode e o que não se deve.

Para Foucault, o século XX foi incitado a falar do sexo, contudo continuaria preso ás antigas interdições em nova maquiagem, pois o sexo continuaria prestando serviço à burguesia, uma vez que foi na família burguesa o início da problematização sexual de crianças e adolescentes; sendo necessária a medicalização da sexualidade feminina, é ainda o seio da família burguesa o local em que as relações sexuais marcaram alianças de heranças, soma ou divisão de fortunas. Com efeito, as camadas populares escaparam por algum tempo do dispositivo de sexualidade, contudo, sendo vitimadas sob outras resultantes desse dispositivo: "O sexo não é essa parte do corpo que a burguesia teve que desqualificar ou anular para pôr para trabalhar os que ela dominava" ${ }^{5}$. Seria, sim, a continuidade da nobreza, do sangue azul, a manutenção do racismo, mascarado pela preocupação em melhorar a descendência humana.

\footnotetext{
${ }^{5}$ Foucault em História da sexualidade, p 117.
} 
Tanto a compreensão biológica como a histórica compõem partes integrantes de importante processo de compreensão da sexualidade. Assim, faz-se necessária a análise em que o biológico e o histórico não constituam seqüência, como no evolucionismo, mas somem-se de acordo com complexidade crescente á medida que se desenvolvam as tecnologias modernas de poder que tomam a vida como meta principal.

O sexo, então, segundo Foucault, é essa instância que se mostra subjacente a tudo o que somos, que nos fascina pelo poder manifestado e pelo sentido que é ocultado, é a condição ótima tornada necessária pelo dispositivo da sexualidade e seu funcionamento. O sexo é o elemento mais especulativo, mais ideal e, igualmente, mais interior, num dispositivo de sexualidade que o poder organiza em suas captações dos corpos, de sua materialidade, de suas forças, suas energias, e seus prazeres. Assim, com a criação desse elemento imaginário, o sexo, como dispositivo, suscitou um de seus princípios mais fundamentais: o desejo do sexo, o desejo de possuí-lo, de descobri-lo, libertá-lo, articulá-lo em discurso e formulálo em verdade.

De acordo com a importância do papel lingüístico no sexual, podemos conceber que, com a palavra, o ser humano deixou sua condição eminentemente biológica de animal silvestre, deixou também de ser regido e ordenado eminentemente pelas leis da natureza, ganhando o status de ser falante, e a natureza humana, desnaturada pelos símbolos, passa a ser regida pela lei do significante. Então, faz-se necessário observar e sensibilizar a anterioridade dos acontecimentos: “...no princípio, era o verbo, e o verbo se fez carne...".

\section{Referências}

BIRMAN, Joel. Entre cuidado e saber de si: sobre Foucault e a psicanálise. Rio de Janeiro: Relume Dumará, 2000.

FOUCAULT Michel. História da sexualidade. Vol.I, 14. ed. Rio de Janeiro: Graal, 2001.

—. Microfísica do poder. 8. ed. Rio de Janeiro: Graal, 1989.

FREUD, Sigmund. Um caso de histeria, três ensaios sobre a sexualidade e outros trabalhos. E.S.B., Vol VII, Rio de Janeiro: Imago, 1996.

GARCIA, José C. Problemáticas da identidade sexual-clínica psicanalítica. São Paulo: Casa do Psicólogo, 2001.

HIGHWATER, Jamake. Mito e sexualidade. São Paulo: Saraiva, 1992.

NASCIMENTO, Renan C. Apostila do Curso de Formação em Psicossomática. Brasília: 2004. 